\title{
Fc receptor-like 1, 3, and 6 variants are associated with rheumatoid arthritis risk in the Chinese Han population
}

Yonghui Yang ${ }^{1}$, Dandan $\mathrm{Li}^{2}$, Chunjuan He${ }^{2}$, Linna Peng ${ }^{2}$, Shishi Xing ${ }^{2}, \mathrm{Mei} \mathrm{Bai}^{2}$, Hao Rong ${ }^{2}$, Dongya Yuan², Yongjun $\mathrm{He}^{2}$, Xue He${ }^{2}$, Li Wang ${ }^{2}$ and Tianbo $\operatorname{Jin}^{2^{*}}$ (D)

\begin{abstract}
Background: Rheumatoid arthritis (RA) is the most common autoimmune system diseases in our world. More studies in recent years have shown that FCRL gene polymorphisms is closely related to autoimmune diseases. It is suggested that genetic factors play a crucial role in the pathogenesis of this disease. In this study, we aimed to investigate the relationship between FCRL1 rs2050568, FCRL3 rs2317230 and FCRL6 rs58240276 polymorphisms and RA risk in the Chinese Han population. 506 with RA patients and 509 healthy controls were recruited in this study, and the single nucleotide polymorphisms (SNPs) was successfully genotyped using the Agena MassARRAY platform. Odds ratios (ORs) and $95 \%$ confidence intervals (95\% Cls) after adjusting for age and gender were conducted to assess these SNPs polymorphisms and RA risk. The multifactor dimensionality reduction (MDR) method was conducted to analyze SNP-SNP interaction.
\end{abstract}

Results: Our results revealed that there no significant association was observed between the allele and genotype frequencies among these SNPs and RA risk (all $p>0.05$ ). Straified analysis by age and gender, the results confirmed that FCRL 1 rs2050568 T/T genotype enhanced the risk of RA in females $(p=0.014)$. The $\mathrm{G} / \mathrm{T}-\mathrm{T} / \mathrm{T}$ genotype of FCRL3 rs 2317230 was correlated with a decreased RA risk in males $(p=0.021)$. We also observed that the $C / T-T / T$ genotype of FCRL 6 rs58240276 was increased the risk of RA in the group at age $>54$ years ( $p=0.016)$. In addition, FCRL1 rs2050568-TT, FCRL6 rs58240276-TT and FCRL1 rs2050568-TT, FCRL3 rs2317230-TT, FCRL6 rs58240276-TT are the best models for multi-site MDR analysis $(p<0.05)$, and the two best models mentioned above and classes RA have the most significant correlation.

Conclusions: Our study demonstrated that FCRL1 rs2050568, FCRL3 rs2317230, and FCRL6 rs58240276 polymorphisms were correlated with RA susceptibility in the Chinese Han population.

Keywords: RA, FCRL1, FCRL3, FCRL6, Polymorphisms

\footnotetext{
* Correspondence: jintb@nwu.edu.cn

${ }^{2}$ Key Laboratory of Molecular Mechanism and Intervention Research for Plateau Diseases of Tibet Autonomous Region, School of Medicine, Xizang Minzu University, \#6 East Wenhui Road, Xianyang 712082, Shaanxi, China Full list of author information is available at the end of the article
} 


\section{Introduction}

Rheumatoid arthritis (RA) one of the most concerning inflammatory diseases with its frequency, chronicity, and system characterized by synovial destruction and joint inflammation, which leads to reduce the quality of life and even causes to the disability $[1,2]$. It was estimated that the prevalence of RA was more than $0.8 \%$ in the our world [3]. Up to now, the etiologies of RA remain unknown. Recently, numerous epidemiologic studies confirmed that genetic factorsone of the two essential and fundamental factors that environment factor is the other, may play an important role in the occurrence and development of RA [4, 5]. Moreover, increasing genomewide association studies (GWAS) have been identified more than hundreds of single-nucleotide polymorphisms (SNPs) correlated with autoimmune diseases, such as ankylosing spondylitis (AS), juvenile idiopathic arthritis (JIA), and RA [6-8].

Fc receptor-like $(F C R L)$ gene family a new member of the Ig superfamily, which encodes the protein may play an essential role in regulating B signaling [9]. It is reported that the extracellular part of FCRL molecules contains multiples numbers of Ig-like domains and their cytoplasmictail contains immunoreceptor tyrosine-based activation motifs (ITAMs) and immunoreceptor tyrosine-based inhibitory motifs (ITIMs) [10]. In addition, the FCRL gene family contained six members with FCRL1, FCRL2, FCRL3, FCRL4, FCRL5 and FCRL6. FCRL1-5 was significantly expressed by B cells. However FCRL6 was expressed by $\mathrm{T}$ cells and NK cells [11]. To date, the FCRL gene expression has been extensively assessed in human malignancies involving mantle cell lymphoma and multiple myeloma $[12,13]$. Nowadays, increasing researches have been provided many evidences which demonstrated that FCRL gene polymorphisms, especially FCRL3, were associated with various autoimmune diseases including AS and RA [14-16]. Okada et al. [17] conducted a European-specific and Asian-specific GWAS meta-analysis by evaluating about 10 million SNPs, and found 42 new RA risk sites at the genome-wide significance level. Among them, the T/G genotype of FCRL3 rs2317230 polymorphism significantly increased the risk of RA in the European and Asian populations $(\mathrm{OR}=1.07,95 \% \mathrm{CI}=1.04$ $1.10, p=1.0 \mathrm{E}-05, \mathrm{OR}=1.10,95 \% \mathrm{CI}=1.04-1.16, p=3.1 \mathrm{E}-04$, respectively). Therefore, the FCRL3 rs2317230 polymorphism is associated with the risk of RA in the Europeans and Asians populations.

Through performed a case-control analysis comprising 506 patients with RA and 509 healthy controls in the Chinese Han population, our study is the first to elucidate the relationship between FCRL1 rs2050568, FCRL3 rs2317230, FCRL6 rs58240276 polymorphisms and RA in the Chinese Han population.

\section{Material and methods Subjects}

All individuals including 506 patients with RA and 509 healthy controls were enrolled from the Yanliang 630 hospital from the October 2016 to January 2019. All the individuals were unrelated Chinese Han people. In the current study, we performed the same exclusion criterion: any patients and healthy controls having cancer, transplantation or other autoimmune diseases were excluded. In addition, this study was conducted in accordance with the Declaration of Helsinki and the protocol was approved by the Ethics Committee of the Affiliated Hospital of Xizang Minzu University. In the same vein, written informed consents were obtained from all subjects.

\section{DNA extraction and genotyping}

Five whole blood samples were available from each participants. According to the manufacturer's instructions, genomic DNA was extracted from whole blood samples using the GoldMag-Mini Whole Blood Genomic DNA Purification Kit (GoldMag. Co. Ltd., Xi'an, China). The DNA concentration and purity were assessed using spectrophotometer (NanoDrop 2000; Thermo Fisher Scientific, Waltham, MA, USA). In this study, FCRL1 rs2050568, FCRL3rs2317230, and FCRL6 rs58240276 were chose to investigate the influence on the risk of RA from the 1000 Genomes Project (http:// www.1000genomes.org/) with the minor allele frequency $(\mathrm{MAF})>5 \%$ [18]. The amplification and extension primers were performed through the Agena Bioscience Assay Design Suite V2.0 software (https://agenacx.com/online-tools/), following the guideline. Subsequently, SNPs genotyping and data analysis were conducted using the Agena MassARRAY platform (Agena Bioscience, San Diego, CA, USA) and Agena Bioscience TYPER version 4.0, respectively.

\section{Statistical analyses}

SPSS 20.0 (SPSS, Chicago, IL, USA) software was used for statistical analysis [19]. For all subjects, the difference of age and gender was applied by the Pearson's chisquare test and independent sample Student's t-test. Among the healthy controls, the genotype frequencies were calculated to evaluate the departure from HardyWeinberg equilibrium (HWE) using the chi-square test. In addition, the relationship between these SNPs and RA risk was estimated with the values of odds ratios (ORs) and 95\% confidence intervals (CIs) using the logistic regression analysis after adjusting for age and gender. The analysis was conducted by the PLINK 1.07 software [20]. All $p$ values were two-sided, and $p<0.05$ was considered to be statistically significant. In addition, we used multifactor dimensionality reduction (MDR, version 3.0.2) to evaluate the impact of SNP - SNP interaction on the risk of RA. This method can reveal the high-order interactions between genes related to a specific phenotype, 
thereby identifying multilocus genotype combinations which are related a high or low risk of disease. The $p$ value analyzed using MDR software was calculated using the $x^{2}$ test.

\section{Results}

\section{Characteristics of subjects}

In the current study, 506 patients with RA (135 males and 371 females, mean age $54.35 \pm 11.69$ years) and 509 unrelated healthy controls (134 males and 375 females, mean age: $54.39 \pm 12.02$ years) were recruited. No significant difference in the distribution of gender between the patients and healthy controls was observed $(p>0.958)$. However, we found that the distribution of age between the two groups was significant difference $(p=0.038)$. Subsequently, we further analyzed the clinical parameters among 506 patients with RA. The mean \pm SD of CRP, RF, ESR, and CCP were $31.05 \pm 40.25 \mathrm{mg} / \mathrm{L}$, $164.09 \pm 147.21 \mathrm{KIU} / \mathrm{L}, 44.28 \pm 30.86 \mathrm{~mm} / \mathrm{h}$ and $75.11 \pm$ $60.78 \mathrm{RU} / \mathrm{ml}$, respectively. The characteristics of patients and healthy controls are summarized in Table 1.

\section{Association between SNPs and RA risk}

The detailed information including SNP ID, position, gene, allele, MAF, and HWE $p$-value is displayed in Table 2. Our results suggested that the genotype distribution of all candidate SNPs was in accordance with HWE among the healthy controls group (all $p>0.05$ ). Furthermore, the MAF of these SNPs was not significantly associated with RA risk in the Chinese Han population $(p>0.05)$. In order to further evaluate the relationship between FCRL1 rs2050568, FCRL3 rs2317230, FCRL6 rs58240276 polymorphisms and RA risk, three different genetic models such as the dominant, the recessive and the log-additive models after adjusting for age

Table 1 Characteristics of cases and controls

\begin{tabular}{llll}
\hline Variables & Cases $(\boldsymbol{n}=\mathbf{5 0 6})$ & Controls $(\boldsymbol{n}=\mathbf{5 0 9})$ & $\boldsymbol{p}$ \\
\hline Age, years (mean \pm SD) & $59.80 \pm 9.08$ & $59.80 \pm 10.63$ & $0.038^{*}$ \\
$\quad \leq 54$ & $262(51.78 \%)$ & $260(51.08 \%)$ & \\
$>54$ & $244(48.22 \%)$ & $249(48.92 \%)$ & \\
Gender & & & 0.958 \\
$\quad$ Male & $135(26.68 \%)$ & $134(26.33 \%)$ & \\
$\quad$ Female & $371(73.32 \%)$ & $375(73.67 \%)$ & \\
Clinical parameters & & & \\
CRP (mg/L) & $31.05 \pm 40.25$ & & \\
RF (KIU/L) & $164.09 \pm 147.21$ & & \\
ESR (mm/h) & $44.28 \pm 30.86$ & & \\
CCP $(\mathrm{RU} / \mathrm{ml})$ & $75.11 \pm 60.78$ & & \\
\hline
\end{tabular}

SD: standard deviation; RA: rheumatoid arthritis; SD: standard deviation; CRP: C-reaction protein; RF: rheumatoid factor; ESR: erythrocyte sedimentation rate; CCP: anti-cyclic citrullinated peptide

$p$ values were calculated from $x^{2}$ test

${ }^{*} p<0.05$ indicates statistical significance and gender were performed. Nevertheless, no significant correlation between the three SNPs polymorphisms and the risk of RA was observed in this study (Table 3).

\section{Stratification analysis on the association between SNPs and $\mathrm{RA}$ risk}

When the stratification analysis by age was conducted, the results suggested that the $\mathrm{C} / \mathrm{T}-\mathrm{T} / \mathrm{T}$ genotype of FCRL6 rs58240276 polymorphism was significant increased the risk of RA in the old group at age > 54 years in under the dominant model $(\mathrm{OR}=1.54,95 \% \mathrm{CI}=1.08-2.19, p=0.016)$. We also observed that FCRL6 rs58240276 polymorphism was associated with an increased improved the risk of RA in the old group at age $>54$ years in the log-additive model $(\mathrm{OR}=$ $1.41,95 \% \mathrm{CI}=1.05-1.89, p=0.021$ ). However, no significant differences were found between FCRL1 rs2050568 and FCRL3 rs2317230 polymorphism and RA risk under the stratification analysis among three genetic models. The results are presented in Table 4.

Subsequently, stratification analysis by gender was performed. Our results confirmed that FCRL1 rs2050568 T/ $\mathrm{T}$ genotype enhanced the risk of RA in females under the recessive model $(\mathrm{OR}=1.64,95 \% \mathrm{CI}=1.10-2.45, p=$ $0.014)$. On the contrary, the $G / T-T / T$ genotype of FCRL3 rs2317230 was correlated with decreased RA risk in males in the dominant model $(\mathrm{OR}=0.5695 \% \mathrm{CI}=$ $0.34-0.92, p=0.021$ ). For FCRL6 rs58240276, we not observed that any association between the SNP polymorphism and RA risk in gender stratification (Table 5).

\section{SNP - SNP interactions using MDR analysis with RA risk}

The MDR method was conducted to analyze SNP - SNP interaction. We used MDR analysis to assess the impact of the SNP - SNP interaction between the three selected SNPs in the FCRL (Table 6). The higher the "CV Consistency" and "Accuracy" values, the greater the interaction between SNPs. We found three models in total and found that FCRL1 rs2050568-TT, FCRL3 rs2317230-TT, and FCRL6 rs58240276-TT are the best models for multi - site MDR analysis (CV consistency = $10 / 10$, accuracy $=0.541, p<0.01$ ). In addition, models with FCRL1 rs2050568 and FCRL6 rs58240276 increase the risk of RA. Next, we used the interaction dendrogram of the entire genotype data set to show the SNP SNP interaction between these two genes. As shown in Fig. 1, the bluer the color, the stronger the redundancy between SNPs. Conversely, the redder the color, the stronger the synergy between the sites. And in the risk analysis of RA, it can be observed that there is a strong redundancy between rs2050568 and rs2317230. It can be seen from Fig. 2 that there is a synergy between rs58240276 and rs2317230. 
Table 2 Basic characteristics and allele frequencies among these SNPS

\begin{tabular}{|c|c|c|c|c|c|c|c|c|}
\hline \multirow[t]{2}{*}{ SNP } & \multirow[t]{2}{*}{ Gene } & \multirow[t]{2}{*}{ Chr } & \multirow[t]{2}{*}{ Allele } & \multicolumn{2}{|l|}{ MAF } & \multirow{2}{*}{$\begin{array}{l}\text { HWE } \\
p- \\
\text { Value }\end{array}$} & \multirow[t]{2}{*}{ OR(95\% Cl) } & \multirow[t]{2}{*}{$p$} \\
\hline & & & & Case & Control & & & \\
\hline rs2050568 & FCRL1 & 1 & $\mathrm{~T} / \mathrm{C}$ & 0.23 & 0.20 & 0.891 & $1.17(0.94-1.44)$ & 0.155 \\
\hline rs2317230 & FCRL3 & 1 & $\mathrm{~T} / \mathrm{G}$ & 0.37 & 0.37 & 0.924 & $1.03(0.86-1.23)$ & 0.775 \\
\hline rs58240276 & FCRLG & 1 & $\mathrm{~T} / \mathrm{C}$ & 0.23 & 0.20 & 0.891 & $1.17(0.94-1.44)$ & 0.155 \\
\hline
\end{tabular}

Cl: confidence interval; HWE: Hardy-Weinberg equilibrium; MAF: minor allele frequency; OR: odds ratio; SNP: single nucleotide polymorphism

* Sites with HWE $(p<0.05)$ are excluded

$P^{a}$ values is calculated with two-sided $x^{2}$

${ }^{*} p^{a}<0.05$ indicates statistical significance

\section{Discussion}

RA is a most typical autoimmune disease, and affected by various genetic and environmental factors. Multiples studies revealed that genetic factors can lead to the risk of RA and various SNPs, which have been confirmed to be associated with the susceptibility of RA [21]. Up to now, the contribution of the SNPs such as FCRL1 rs2050568, FCRL3 rs2317230, and FCRL6 rs58240276 to RA risk remained unclear. In the current study, we performed a case-control study to clarify the relationship between FCRL1 rs2050568, FCRL3 rs2317230, FCRL6 rs58240276 polymorphisms and RA susceptibility in the Chinese Han population. Eventually, our results suggested that these SNPs were associated with the risk of RA in different stratification by age and gender.

The FCRL family gene is located in $1 \mathrm{p} 21-23$ region, and may play a crucial role in regulation of the $\mathrm{B}$ cell signaling [22]. Mutations in FCRL gene have been reported to be correlated with numerous human diseases, including grave disease and immune system disease [23-
25]. A study reported that the expressions of activating or inhibitory FCRL1, 2, and 4 revealed alterations in graves' disease patients compared to healthy subjects [26]. Recently, a meta-analysis which including 916 patients with RA and 3746 healthy controls was performed, the results suggested that FCRL3 rs17727339 showed significant correlations with RA risk [16]. In addition, Kochi et al. reported that FCRL3 variant $(-169 C)$ was associated with RA risk in the Japanese population [24]. Whereas, a subsequent research suggested that this association was not reproduced among a Spanish and numerous US-based RA case-control subjects [25, 27]. There are differences in the incidence of FCRL gene polymorphisms MAF and RA between the Chinese Han population and the other populations. Ramírez-Bello et al. explored the relationship between FCRL3 polymorphism and juvenile rheumatoid arthritis (JRA) in the Mexican population and found that FCRL3_3 (rs7528684) and FCRL3_6 (rs3761959) showed significant MAF difference ( $p=0.03$ and $p=0.01$, respectively).

Table 3 Association between SNPs genotypes and RA risk

\begin{tabular}{|c|c|c|c|c|c|c|}
\hline SNP & Model & Genotype & Cases & Controls & OR $(95 \% \mathrm{Cl})$ & $P$ \\
\hline rs2050568 & Dominant & $\mathrm{C} / \mathrm{C}$ & 184 & 184 & 1 & \\
\hline \multirow[t]{4}{*}{ FCRL1 } & & $\mathrm{C} / \mathrm{T}-\mathrm{T} / \mathrm{T}$ & 322 & 325 & $0.99(0.77-1.28)$ & 0.945 \\
\hline & Recessive & $\mathrm{C} / \mathrm{C}-\mathrm{C} / \mathrm{T}$ & 436 & 441 & 1 & \\
\hline & & $\mathrm{T} / \mathrm{T}$ & 70 & 68 & $1.40(0.99-1.98)$ & 0.060 \\
\hline & Log-additive & & & & $1.09(0.91-1.31)$ & 0.348 \\
\hline rs2317230 & Dominant & $\mathrm{G} / \mathrm{G}$ & 197 & 202 & 1 & \\
\hline \multirow[t]{4}{*}{ FCRL3 } & & $\mathrm{G} / \mathrm{T}-\mathrm{T} / \mathrm{T}$ & 309 & 307 & $1.03(0.80-1.33)$ & 0.806 \\
\hline & Recessive & $\mathrm{G} / \mathrm{G}-\mathrm{G} / \mathrm{T}$ & 419 & 443 & 1 & \\
\hline & & $\mathrm{T} / \mathrm{T}$ & 87 & 66 & $1.04(0.73-1.49)$ & 0.821 \\
\hline & Log-additive & & & & $1.03(0.86-1.23)$ & 0.771 \\
\hline rs58240276 & Dominant & $\mathrm{C} / \mathrm{C}$ & 300 & 325 & 1 & \\
\hline \multirow[t]{4}{*}{ FCRL6 } & & $\mathrm{C} / \mathrm{T}-\mathrm{T} / \mathrm{T}$ & 206 & 184 & $1.21(0.94-1.56)$ & 0.137 \\
\hline & Recessive & $\mathrm{C} / \mathrm{C}-\mathrm{C} / \mathrm{T}$ & 482 & 488 & 1 & \\
\hline & & $\mathrm{T} / \mathrm{T}$ & 24 & 21 & $1.16(0.63-2.11)$ & 0.636 \\
\hline & Log-additive & & & & $1.17(0.94-1.45)$ & 0.155 \\
\hline
\end{tabular}

$\mathrm{Cl}$ : confidence interval; OR, odds ratio; SNP: single nucleotide polymorphism ${ }^{*} p<0.05$ indicates statistical significance 
Table 4 Association between SNPS and RA risk were stratified for age

\begin{tabular}{|c|c|c|c|c|c|c|}
\hline \multirow[t]{2}{*}{ SNP } & \multirow[t]{2}{*}{ Model } & \multirow[t]{2}{*}{ Genotype } & \multicolumn{2}{|l|}{$\leq 54$} & \multicolumn{2}{|l|}{$>54$} \\
\hline & & & OR $(95 \% \mathrm{Cl})$ & $P$ & OR $(95 \% \mathrm{Cl})$ & $P$ \\
\hline rs2050568 & Dominant & $\mathrm{C} / \mathrm{C}$ & 1 & & 1 & \\
\hline \multirow[t]{4}{*}{ FCRL 1} & & $\mathrm{C} / \mathrm{T}-\mathrm{T} / \mathrm{T}$ & $0.90(0.62-1.31)$ & 0.592 & $1.08(0.76-1.54)$ & 0.656 \\
\hline & Recessive & $\mathrm{C} / \mathrm{C}-\mathrm{C} / \mathrm{T}$ & 1 & & 1 & \\
\hline & & $\mathrm{T} / \mathrm{T}$ & $1.42(0.87-2.34)$ & 0.165 & $1.43(0.87-2.34)$ & 0.154 \\
\hline & Log-additive & & $1.05(0.81-1.37)$ & 0.715 & $1.14(0.89-1.47)$ & 0.296 \\
\hline rs2317230 & Dominant & $\mathrm{G} / \mathrm{G}$ & 1 & & & \\
\hline \multirow[t]{4}{*}{ FCRL3 } & & $\mathrm{G} / \mathrm{T}-\mathrm{T} / \mathrm{T}$ & $1.10(0.76-1.59)$ & 0.605 & $0.98(0.69-1.40)$ & 0.929 \\
\hline & Recessive & $\mathrm{G} / \mathrm{G}-\mathrm{G} / \mathrm{T}$ & 1 & & & \\
\hline & & $\mathrm{T} / \mathrm{T}$ & $0.85(0.50-1.46)$ & 0.561 & $1.26(0.77-2.05)$ & 0.360 \\
\hline & Log-additive & & $1.01(0.77-1.33)$ & 0.930 & $1.05(0.82-1.35)$ & 0.689 \\
\hline rs58240276 & Dominant & $\mathrm{C} / \mathrm{C}$ & 1 & & 1 & \\
\hline \multirow[t]{4}{*}{ FCRL6 } & & $\mathrm{C} / \mathrm{T}-\mathrm{T} / \mathrm{T}$ & $0.93(0.64-1.34)$ & 0.697 & $1.54(1.08-2.19)$ & 0.016 \\
\hline & Recessive & $\mathrm{C} / \mathrm{C}-\mathrm{C} / \mathrm{T}$ & 1 & & 1 & \\
\hline & & $\mathrm{T} / \mathrm{T}$ & $0.80(0.29-2.18)$ & 0.662 & $1.43(0.67-3.06)$ & 0.355 \\
\hline & Log-additive & & $0.92(0.67-1.28)$ & 0.631 & $1.41(1.05-1.89)$ & 0.021 \\
\hline
\end{tabular}

Cl: confidence interval; OR: odds ratio; SNP: single nucleotide polymorphism

${ }^{*} p<0.05$ indicates statistical significance

The protective effect of FCRL3 gene SNP on JRA disease in Mexican male patients [28]. There is a significant difference in the FCRL3 -69 T > C (rs7528684) in the Chinese population $(p=0.003)$, and the MAF of $1381 \mathrm{G}>\mathrm{A}$ (rs3761959) is not significantly different $(p=0.493)$. The FCRL3-169 T/C variant and the RA in the Chinese Han population is significantly related to an increased risk [29]. In our study, our study confirmed that the allele and genotype frequencies of FCRL1 rs2050568, FCRL3 rs2317230 and FCRL6 rs58240276 were not interacted with RA risk in the Chinese Han population. Subsequently, we performed stratification analysis by age and gender. The results demonstrated that the $\mathrm{C} / \mathrm{T}-\mathrm{T} / \mathrm{T}$ genotype of FCRL6 rs58240276 polymorphism was increased the risk of RA in age $>54$ years $(p=0.016)$. During the same time, we also confirmed that FCRL1

Table 5 Association between SNPs and RA risk were stratified for gender

\begin{tabular}{|c|c|c|c|c|c|c|}
\hline \multirow[t]{2}{*}{ SNP } & \multirow[t]{2}{*}{ Model } & \multirow[t]{2}{*}{ Genotype } & \multicolumn{2}{|l|}{ Male } & \multicolumn{2}{|l|}{ Female } \\
\hline & & & OR $(95 \% \mathrm{Cl})$ & $P$ & OR $(95 \% \mathrm{Cl})$ & $P$ \\
\hline rs2050568 & Dominant & $\mathrm{C} / \mathrm{C}$ & 1 & & 1 & \\
\hline \multirow[t]{4}{*}{ FCRL1 } & & $\mathrm{C} / \mathrm{T}-\mathrm{T} / \mathrm{T}$ & $0.89(0.54-1.46)$ & 0.648 & $1.03(0.76-1.39)$ & 0.842 \\
\hline & Recessive & $\mathrm{C} / \mathrm{C}-\mathrm{C} / \mathrm{T}$ & 1 & & 1 & \\
\hline & & $\mathrm{T} / \mathrm{T}$ & $0.80(0.38-1.69)$ & 0.564 & $1.64(1.10-2.45)$ & 0.014 \\
\hline & Log-additive & & $0.89(0.62-1.28)$ & 0.533 & $1.17(0.95-1.43)$ & 0.150 \\
\hline rs2317230 & Dominant & $\mathrm{G} / \mathrm{G}$ & 1 & & & \\
\hline \multirow[t]{4}{*}{ FCRL3 } & & $\mathrm{G} / \mathrm{T}-\mathrm{T} / \mathrm{T}$ & $0.56(0.34-0.92)$ & 0.021 & $1.29(0.96-1.73)$ & 0.092 \\
\hline & Recessive & $\mathrm{G} / \mathrm{G}-\mathrm{G} / \mathrm{T}$ & 1 & & & \\
\hline & & $\mathrm{T} / \mathrm{T}$ & $0.85(0.38-1.87)$ & 0.678 & $1.10(0.74-1.65)$ & 0.636 \\
\hline & Log-additive & & $0.69(0.47-1.00)$ & 0.051 & $1.16(0.95-1.43)$ & 0.153 \\
\hline rs58240276 & Dominant & $\mathrm{C} / \mathrm{C}$ & 1 & & 1 & \\
\hline \multirow[t]{4}{*}{ FCRL6 } & & $\mathrm{C} / \mathrm{T}-\mathrm{T} / \mathrm{T}$ & $1.30(0.80-2.11)$ & 0.292 & $1.18(0.88-1.59)$ & 0.274 \\
\hline & Recessive & $\mathrm{C} / \mathrm{C}-\mathrm{C} / \mathrm{T}$ & 1 & & 1 & \\
\hline & & $\mathrm{T} / \mathrm{T}$ & $1.35(0.45-3.99)$ & 0.593 & $1.08(0.53-2.22)$ & 0.835 \\
\hline & Log-additive & & $1.25(0.83-1.87)$ & 0.282 & $1.14(0.88-1.47)$ & 0.317 \\
\hline
\end{tabular}

Cl: confidence interval; OR: odds ratio; SNP: single nucleotide polymorphism ${ }^{*} p<0.05$ indicates statistical significance 
Table 6 MDR analysis of SNP-SNP interactions in FCRL gene

\begin{tabular}{|c|c|c|c|c|c|c|c|c|}
\hline Model & $\begin{array}{l}\text { Training Bal. } \\
\text { Acc. }\end{array}$ & $\begin{array}{l}\text { Testing Bal. } \\
\text { Acc. }\end{array}$ & $\begin{array}{l}\text { CV } \\
\text { Consistency }\end{array}$ & Accuracy & Sensitivity & Specificity & OR $(95 \% \mathrm{Cl})$ & $p$ \\
\hline rs58240276 & 0.527 & 0.492 & $6 / 10$ & 0.525 & 0.408 & 0.641 & $\begin{array}{l}1.23(0.96- \\
1.59)\end{array}$ & 0.11 \\
\hline rs2050568,rs58240276 & 0.539 & 0.514 & $10 / 10$ & 0.538 & 0.363 & 0.712 & $\begin{array}{l}1.41(1.08- \\
1.83)\end{array}$ & $0.01 *$ \\
\hline rs2050568,rs2317230,rs58240276 & 0.545 & 0.490 & $10 / 10$ & 0.541 & 0.391 & 0.692 & $\begin{array}{l}1.44(1.11- \\
1.87)\end{array}$ & $0.0057^{*}$ \\
\hline
\end{tabular}

Abbreviation: MDR: multifactor dimensionality reduction; SNP: single nucleotide polymorphism; CV: cross-validation; OR: odds ratio; Cl: confidence interval Note: $p$ is calculated using $x^{2}$ test. All $p$-values in this study are two-tailed. Bold values mean statistical significance. ${ }^{*} p<0.05$ indicates statistical significance

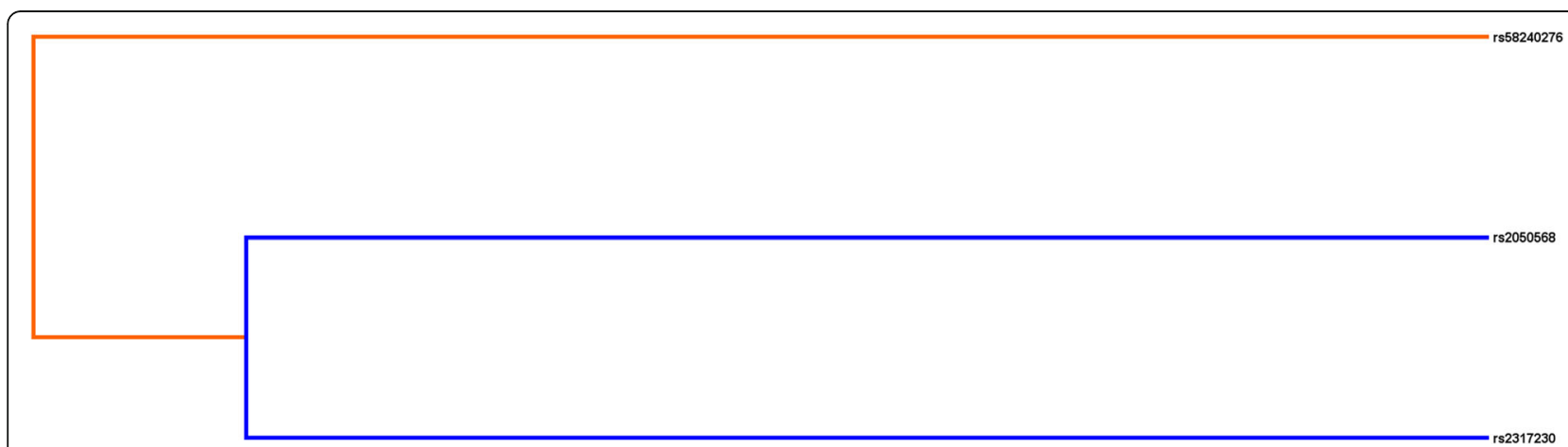

Fig. 1 SNP-SNP Interaction Dendrogram

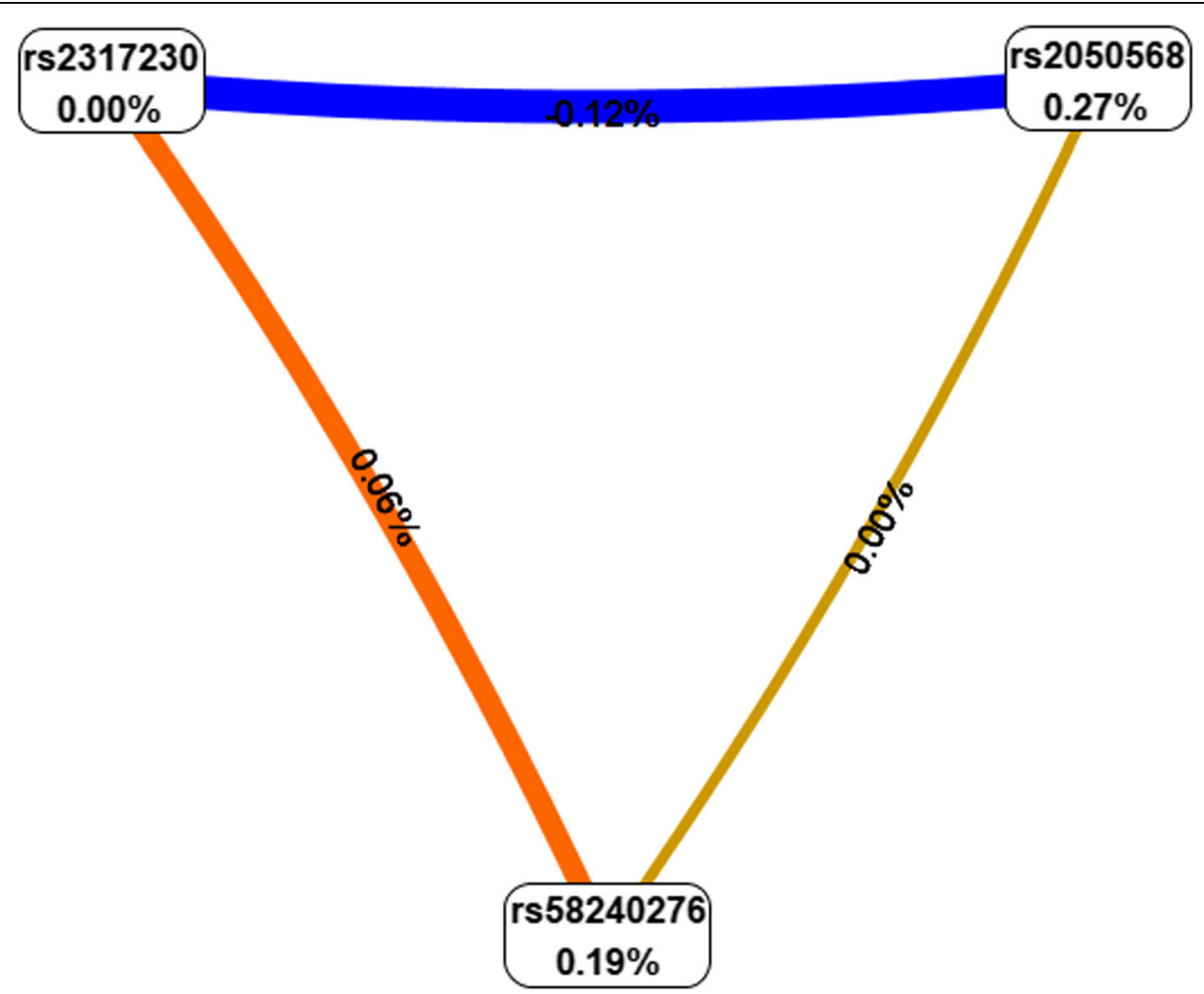

Fig. 2 Fruchterman-Reingold, Describing Interactions Between the Three Genetic Variants 
rs2050568 T/T genotype enhanced the risk of RA in females $(p=0.014)$. In contrast, the $\mathrm{G} / \mathrm{T}-\mathrm{T} / \mathrm{T}$ genotype of FCRL3 rs2317230 was correlated with a decreased RA risk in males $(p=0.021)$.

Various limitations need to be considered in our study, such as the information of samples was little. All in all, we demonstrated that FCRL1 rs2050568 T/T genotype, FCRL3 rs2317230 G/T - T/T genotype, and FCRL6 rs58240276 T/T genotype were associated with RA risk in Chinese Han people, when the stratified analysis by age and gender was performed. Our study provided a new insight into the pathogenesis of this disease. In the future, the detailed molecular mechanism by which the above mentioned polymorphisms influencing the occurrence and development of RA was necessary to be investigated.

\section{Conclusions}

In a word, we firstly provided new evidence for the relationship between the selected variants and RA risk, which may support for the screening of RA in the Han Chinese population and shed light on the mechanism of RA.

\section{Abbreviations}

RA: Rheumatoid arthritis; SNP: Single nucleotide polymorphism; OR: Odds ratio: Cl: Confidence interval; MDR: Multifactor Dimensionality Reduction; GWAS: Genome-wide association study; MAF: Minor allele frequency; EDTA: Ethylenediamine tetraacetic acid; HWE: Hardy-Weinberg equilibrium; LD: Linkage disequilibrium

\section{Supplementary Information}

The online version contains supplementary material available at https://doi. org/10.1186/s41021-021-00213-2.

Additional file 1: Supplementary Table 1. False-Positive Report Probability Values for Associations Between the Risk of rheumatoid arthritis and the Frequency of Variants and Model of FCRL Gene in the Chinese Han population.

\section{Acknowledgements}

We appreciate the Yan liang 630 hospital, which provided the samples used in this study. We also appreciate the reviewers and editors for their efforts and patience.

\section{Authors' contributions}

TJ and LW conceived and designed the experiments. YY, DL, CH, LP and SX performed the experiments. $Y Y, M B, H R$ and DY analyzed the data. $Y H, X H$ wrote the paper. All authors read and approved the final manuscript.

\section{Funding}

This study was funded by the National Natural Science Foundation of China (No. 81960291) and major project training plan of Xizang Minzu University (No. 20MDT01).

\section{Availability of data and materials}

All data generated or analysed during this study are included in this published article.

\section{Declarations}

\section{Ethics approval and consent to participate}

This case-control study was conducted in accordance with the Declaration of Helsinki. And the protocol was approved by the Ethics Committee of the Xizang Minzu University. Written informed consents were obtained from all individuals. The procedures were in accordance with the institutional guidelines.

\section{Consent for publication}

All patients agreed to publish the manuscript.

\section{Competing interests}

The authors declare that they have no competing interests.

\section{Author details}

${ }^{1}$ Clinical Laboratory, Xi'an 630 Hospital, Yanliang, Xi'an, Shaanxi, China. ${ }^{2}$ Key Laboratory of Molecular Mechanism and Intervention Research for Plateau Diseases of Tibet Autonomous Region, School of Medicine, Xizang Minzu University, \#6 East Wenhui Road, Xianyang 712082, Shaanxi, China.

Received: 5 May 2021 Accepted: 4 September 2021

Published online: 07 October 2021

\section{References}

1. Mclnnes IB, Schett $G$. The pathogenesis of rheumatoid arthritis. N Engl J Med. 2011;365(23):2205-19. https://doi.org/10.1056/NEJMra1004965.

2. Hu B, Yan X, Liu F, Zhu C, Zhou H, Chen Y, et al. Downregulated expression of PTPN9 contributes to human hepatocellular carcinoma growth and progression. Pathol Oncol Res. 2016;22(3):555-65. https://doi.org/10.1007/ s12253-015-0038-1.

3. Zhang MY, Yang XK, Lv TT, Wu J, Xu SZ, Wang JB, et al. Meta-analysis of associations between XRCC1 gene polymorphisms and susceptibility to systemic lupus erythematosus and rheumatoid arthritis. Int J Rheum Dis. 2018;21(1):179-85. https://doi.org/10.1111/1756-185X.12966.

4. Li G, Zhao J, Li B, Ma J, Zhao Q, Wang X, et al. Associations between CCL21 gene polymorphisms and susceptibility to rheumatoid arthritis: a metaanalysis. Rheumatol Int. 2017;37(10):1673-81. https://doi.org/10.1007/s00296017-3784-4

5. Qiu Q, Huang J, Shu X, Fan H, Zhou Y, Xiao C. Polymorphisms and pharmacogenomics for the clinical efficacy of methotrexate in patients with rheumatoid arthritis: a systematic review and Meta-analysis. Sci Rep. 2017; 7(1):44015. https://doi.org/10.1038/srep44015.

6. Peeters JGC, Vastert SJ, van Wijk F, van Loosdregt J. Review: enhancers in autoimmune arthritis: implications and therapeutic potential. Arthritis Rheumatol. 2017;69(10):1925-36. https://doi.org/10.1002/art.40194.

7. Morris DL, Sheng Y, Zhang Y, Wang YF, Zhu Z, Tombleson P, et al. Genomewide association meta-analysis in Chinese and European individuals identifies ten new loci associated with systemic lupus erythematosus. Nat Genet. 2016;48(8):940-6. https://doi.org/10.1038/ng.3603.

8. Ombrello MJ, Remmers EF, Tachmazidou I, Grom A, Foell D, Haas JP, et al. HLA-DRB1*11 and variants of the MHC class II locus are strong risk factors for systemic juvenile idiopathic arthritis. Proc Natl Acad Sci U S A. 2015; 112(52):15970-5. https://doi.org/10.1073/pnas.1520779112.

9. Davis RS. Fc receptor-like molecules. Annu Rev Immunol. 2007;25(1):525-60. https://doi.org/10.1146/annurev.immunol.25.022106.141541.

10. Daëron $M$, Jaeger $S$, du Pasquier L, Vivier E. Immunoreceptor tyrosine-based inhibition motifs: a quest in the past and future. Immunol Rev. 2008:224(1): 11-43. https://doi.org/10.1111/j.1600-065X.2008.00666.x.

11. Kazemi T, Asgarian-Omran H, Memarian A, Shabani M, Sharifian RA, Vossough $\mathrm{P}$, et al. Low representation of fc receptor-like 1-5 molecules in leukemic cells from Iranian patients with acute lymphoblastic leukemia. Cancer Immunol Immunother. 2009;58(6):989-96. https://doi.org/10.1007/ s00262-008-0589-z

12. Kazemi T, Asgarian-Omran H, Hojjat-Farsangi M, Shabani M, Memarian A Sharifian RA, et al. Fc receptor-like 1-5 molecules are similarly expressed in progressive and indolent clinical subtypes of B-cell chronic lymphocytic leukemia. Int J Cancer. 2008;123(9):2113-9. https://doi.org/10.1002/ijc.23751.

13. Zeng Z, Duan Z, Zhang T, Wang S, Li G, Mei Y, et al. Association of FCRL4 polymorphisms on disease susceptibility and severity of ankylosing 
spondylitis in Chinese Han population. Clin Rheumatol. 2012;31(10):1449-54. https://doi.org/10.1007/s10067-012-2028-y.

14. Zeng, Z., et al., Association of FCRL4 polymorphisms on disease susceptibility and severity of ankylosing spondylitis in Chinese Han population. 2012. 31(10): p. 1449-1454.

15. Ombrello, M.J., et al., HLA-DRB1* 11 and variants of the MHC class II locus are strong risk factors for systemic juvenile idiopathic arthritis. 2015. 112(52): p. 15970-15975.

16. Terao C, Ohmura K, Kochi Y, Ikari K, Okada Y, Shimizu M, et al. Anticitrullinated peptide/protein antibody (ACPA)-negative RA shares a large proportion of susceptibility loci with ACPA-positive RA: a meta-analysis of genome-wide association study in a Japanese population. Arthritis Res Ther. 2015;17(1):104. https://doi.org/10.1186/s13075-015-0623-4.

17. Okada Y, et al. Genetics of rheumatoid arthritis contributes to biology and drug discovery. Nature. 2014;506(7488):376-81. https://doi.org/10.1038/na ture12873.

18. Jiri M, Zhang L, Lan B, He N, Feng T, Liu K, et al. Genetic variation in the ABCG2 gene is associated with gout risk in the Chinese Han population. Clin Rheumatol. 2016;35(1):159-63. https://doi.org/10.1007/s10067-015-3105-9.

19. Jin X, Zhang KJ, Guo X, Myers R, Ye Z, Zhang ZP, et al. Fatty acid synthesis pathway genetic variants and clinical outcome of non-small cell lung cancer patients after surgery. Asian Pac J Cancer Prev. 2014;15(17):7097-103. https://doi.org/10.7314/APJCP.2014.15.17.7097.

20. Hu QY, Jin TB, Wang L, Zhang L, Geng T, Liang G, et al. Genetic variation in the TP63 gene is associated with lung cancer risk in the Han population. Tumour Biol. 2014:35(3):1863-6. https://doi.org/10.1007/s13277-013-1248-3.

21. Jacob N, Jacob CO. Genetics of rheumatoid arthritis: an impressionist perspective. Rheum Dis Clin N Am. 2012;38(2):243-57. https://doi.org/10.101 6/j.rdc.2012.05.001.

22. Ehrhardt $G R$, et al. Fc receptor-like proteins (FCRL): immunomodulators of $B$ cell function. Adv Exp Med Biol. 2007;596:155-62. https://doi.org/10.1007/ 0-387-46530-8_14.

23. Rostamzadeh D, Dabbaghmanesh M, Shabani M, Hosseini A, Amirghofran Z. Expression profile of human fc receptor-like 1,2, and 4 molecules in peripheral blood mononuclear cells of patients with Hashimoto's thyroiditis and Graves' disease. Horm Metab Res. 2015;47(9):693-8. https://doi.org/10.1 055/s-0035-1545280.

24. Kochi Y, Yamada R, Suzuki A, Harley JB, Shirasawa S, Sawada T, et al. A functional variant in FCRL3, encoding fo receptor-like 3, is associated with rheumatoid arthritis and several autoimmunities. Nat Genet. 2005;37(5):47885. https://doi.org/10.1038/ng1540.

25. Ikari K, et al. Supportive evidence for a genetic association of the FCRL3 promoter polymorphism with rheumatoid arthritis. Ann Rheum Dis. 2006; 65(5):671-3. https://doi.org/10.1136/ard.2005.043489.

26. Rostamzadeh, D., et al., Expression profile of human Fc receptor-Like 1, 2, and 4 molecules in peripheral blood mononuclear cells of patients with Hashimoto's thyroiditis and Graves' disease. 2015. 47(09): p. 693-698.

27. Martinez A, Sanchez E, Valdivia A, Orozco G, Lopez-Nevot MA, PascualSalcedo D, et al. Epistatic interaction between FCRL3 and NFkappaB1 genes in Spanish patients with rheumatoid arthritis. Ann Rheum Dis. 2006;65(9): 1188-91. https://doi.org/10.1136/ard.2005.048454.

28. Ramirez-Bello J, et al. Juvenile rheumatoid arthritis and asthma, but not childhood-onset systemic lupus erythematosus are associated with FCRL3 polymorphisms in Mexicans. Mol Immunol. 2013;53(4):374-8. https://doi. org/10.1016/j.molimm.2012.09.004.

29. Lin $X$, Zhang $Y$, Chen Q. FCRL3 gene polymorphisms as risk factors for rheumatoid arthritis. Hum Immunol. 2016;77(2):223-9. https://doi.org/10.101 6/j.humimm.2015.12.007

\section{Publisher's Note}

Springer Nature remains neutral with regard to jurisdictional claims in published maps and institutional affiliations.

Ready to submit your research? Choose BMC and benefit from:

- fast, convenient online submission

- thorough peer review by experienced researchers in your field

- rapid publication on acceptance

- support for research data, including large and complex data types

- gold Open Access which fosters wider collaboration and increased citations

- maximum visibility for your research: over $100 \mathrm{M}$ website views per year

At $\mathrm{BMC}$, research is always in progress.

Learn more biomedcentral.com/submissions 